\title{
Comentários sobre o Artigo \\ Modelos GARCH Bayesianos: \\ Métodos Aproximados e Aplicações
}

\section{Beatriz Vaz de Melo Mendes}

Em primeiro lugar gostaria de parabenizar os autores por mais uma excelente contribuição na área da inferência estatística.

$\mathrm{O}$ artigo mergulha os modelos GARCH dentro do contexto dos modelos dinâmicos (não lineares) Bayesianos e propõe técnicas numéricas para a estimação dos seus parâmetros, como o uso da quadratura Gaussiana com grade fixa baseada em toda a informação disponível, e também o uso da forma exponencial da aproximação de Laplace. O texto é de fácil leitura e bem organizado, embora em alguns momentos fosse desejável um esclarecimento maior de conceitos/modelos citados, para facilitar a leitura daqueles não familiarizados com a inferência Bayesiana.

Pelo exposto no texto fica-se com a impressão que inferências para os modelos GARCH dinâmicos seriam inviáveis no caso de $p$, $q>1$. Isto constituiria de fato uma deficiência dos procedimentos de estimação propostos e certamente pesquisas no sentido de viabilizar a implementação das técnicas para os casos mais gerais deveriam ser empreendidas.

Para a aplicação das técnicas os autores necessitam de usar dados padronizados, conforme citado na seção 5.2. Este é um ponto importante pois os estimadores clássicos de locação e escala são fortemente afetados por pontos extremos (Hampel e outros, 1986), e portanto quando usados na padronização de dados, distorcem a distribuição original dos dados, principalmente o comportamento das caudas. 
Finalmente, uma questão fundamental que pode comprometer todos os resultados obtidos, é o fato dos métodos utilizados terem sido implementados sob a suposição de normalidade dos dados. Bem mais preocupante é quando esta suposição é feita na seção 5.2 , onde são analisados os dados reais. Sabe-se (Bollerslev, 1987) que a distribuição marginal de retornos de séries financeiras possui caudas pesadas e que sua distribuição não condicional apresenta momentos não compatíveis com aqueles provenientes de uma especificação (condicional) normal. Conforme sugerem outros autores tais como Bollerslev (1987), Engle e González-Rivera (1991), Nelson (1991), etc, o uso de uma distribuição t-student seria mais apropriado. Usando uma especificação t-student com poucos graus de liberdade $(3,4$ ou 5 , por exemplo), as comparações feitas e mostradas na tabela 6 ficariam mais imparciais.

\section{Referências Bibliográficas}

Bollerslev, T. 1987). "A Conditionally Heteroskedastic Time Series Model for Speculative Prices and Rates of Return". The Review of Economics and Statistics, 69, 542-547.

Engle, R.F. \& González-Rivera, G. (1991). "Semi-parametric Estimation of ARCH Model". Journal of Business and Economic Statistics, 9(4), 345-358.

Hampel, F.R. (1974). "The Influence Curve and Its Role in Robust Estimation". Journal of the American Statistical Association, 69, 383-393.

Nelson, D.B. (1991). "Conditional Heteroscedasticity in Asset Returns". Econometrica, 59, 347-370. 